\title{
Role of Medial Amygdala in Controlling Hemodynamics Via GABAA Receptor in Anesthetized Rats
}

\author{
Seiji Yoshida, MD; Tatsuaki Matsubara, MD; Arata Uemura, MD; \\ Akihisa Iguchi, MD*; Nigishi Hotta, MD
}

\begin{abstract}
Experiments were conducted to determine whether the medial amygdala could control hemodynamics through the GABA receptor in anesthetized rats. Bicuculline (10-100 pmol), a GABAA antagonist, injected into the anterior basomedial amygdala (medial amygdala) produced dose-related increases in blood pressure (BP) and heart rate (HR). Following microinjection of a 100 pmol dose, plasma norepinephrine and epinephrine also rose significantly. In a group that had undergone bilateral adrenalectomy, the same dose of bicuculline into the same region of the amygdala caused similar increases in BP and HR to those produced in normal rats. Pretreatment with an intraperitoneal injection of hexamethonium prevented these responses. When bicuculline was given intravenously $(100 \mathrm{pmol})$ it failed to effect these cardiovascular changes. Bicuculline-induced hypertension and tachycardia were inhibited by microinjection of muscimol, a GABA agonist, into the anterior basomedial amygdala. The results thus demonstrate that the influence of bicuculline on BP and HR is through action on the anterior basomedial amygdala and direct sympathetic outflow to heart and vascular smooth muscle. There is tonic GABAergic inhibition of sympathetic outflow in the medial amygdala that plays a part in regulating hemodynamics in the limbic system. (Circ J 2002; 66: 197-203)
\end{abstract}

Key Words: Anterior basomedial amygdala; Bicuculline methiodide; Blood pressure; GABAA receptor; Heart rate

$\mathbf{I}$ $\mathrm{t}$ is well known that sympathetic outflow regulates blood pressure (BP) and heart rate (HR) via norepinephrine release $\mathrm{e}^{1,2}$ and it has been proposed that the forebrain periventricular GABA system exerts a tonic inhibitory influence over the sympathetic nervous system3,4 Although a number of GABAergic sites are located within the hypothalamus, it has also been demonstrated that the amygdaloid complex has rich neuronal connections with structures in the hypothalamus and medulla oblongata, and is implicated in the control of several autonomic functions including cardiovascular control5-7

Recently, chemical stimulation of the amygdala was shown to produce cardiovascular and behaviour changes? In particular, the GABAA receptor antagonist, bicuculline, revealed the sites in and around the anterior basolateral amygdala that generate the largest response in terms of increased BP and HR? In addition, interactions between anterior basolateral amygdala and muscarinic receptors, glutamate ionotropic receptors and benzodiazepine receptors have been reported 10,11 However, the influence of the anterior basomedial amygdala in the regulation of cardiovascular functions remains unclear.

The amygdala is thought to play a central role in a variety of behavioral, physiological and endocrine responses, ${ }^{12}$ and its structural organization appears to mimic this functional complexity. In rats, there are 2 parts to the basomedial nucleus of the amygdala: anterior and posterior, which oc-

(Received May 21, 2001; revised manuscript received November 5, 2001; accepted November 16, 2001)

Departments of Internal Medicine III and *Geriatric Medicine, Nagoya University School of Medicine, Nagoya, Japan

Mailing address: Tatsuaki Matsubara, MD, Department of Internal Medicine III, Nagoya University School of Medicine, 65 Tsurumaicho, Showa-ku, Nagoya 466-8550, Japan. E-mail: tatmat@med. nagoya-u.ac.jp cupy a considerable fraction of the amygdala. Major inputs to the anterior basomedial amygdala are associated with the relay of olfactory and gustatory information and this section of the organ massively innervates areas projecting to neuroendocrine, autonomic and somatomotor effector systems, probably involved in the expression of some aspects of feeding behavior ${ }^{13}$

The present study was therefore designed to assess the role of the anterior basomedial amygdala in the control of $\mathrm{BP}$ and HR by injecting bicuculline and muscimol, as well as by measurement of plasma catecholamine levels, in anesthetized and bilateral adrenalectomized rats.

\section{Methods}

\section{Animal Preparation}

Male albino Wistar rats (Keary, Nagoya, Japan) weighing 300-350 g were kept in individual cages in a temperature-controlled room at $24^{\circ} \mathrm{C}$ with a 12-h light-dark cycle. They had free access to laboratory chow and water until the start of the experiment. Each rat was anesthetized with urethane $(1.5 \mathrm{~g} / \mathrm{kg}$ body weight, ip). The left femoral artery was cannulated with SP-31 polyethylene tubing filled with physiological saline containing heparin $(75 \mathrm{IU} / \mathrm{ml})$ and which was connected via a transducer (Statham P23ID, Gould, Cleveland, OH, USA) to a polygraph system (Nihon Kohden Co, Tokyo, Japan) for monitoring BP. The R-wave of the ECG (lead II) triggered a cardiotachometer, and BP and HR were recorded continuously on a strip chart recorder (Nihon Kohden Co).

Each rat was then moved onto a stereotaxic apparatus! ${ }^{4,15}$ The skin and muscle overlying the dorsal surface of the skull were removed. The bregma served as the reference point and the stereotaxic coordinates were taken from the atlas of Pellegrino et al ${ }^{16}$ After a small hole was made 


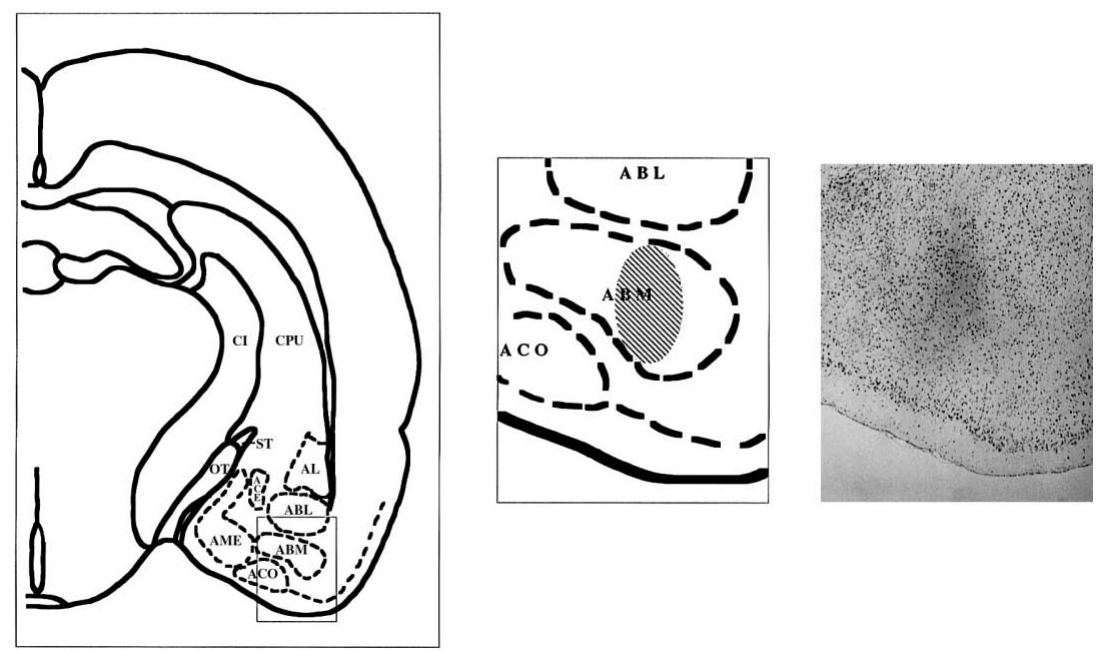

Fig 1. (Left) Schematic representation of coronal section through the right anterior basomedial amygdala. (Center) Schematic diagram of distribution of the dye (hatched area). (Right) Distribution of $0.2 \mu 11 \%$ Evans blue dye injected into the right anterior basomedial amygdala in a $15 \mu \mathrm{m}$ thick coronal section $(\times 40)$. ABL, basal amygdaloid nucleus-lateral part (anterior basolateral amygdala); ABM, basal amygdaloid nucleus-medial part (anterior basomedial amygdala); ACE, central amygdaloid nucleus; ACO, cortical amygdaloid nucleus; AL, lateral amygdaloid nucleus; AME, medial amygdaloid nucleus; CI, internal capsule; CPU, caudate nucleus-putamen; OT, optic tract; ST, stria terminalis.

in the skull with an electric drill, a 30-gauge needle was inserted into the brain. The target for the amygdala was anterior-posterior -0.6 , height-depth -8.5 , and right-left $3.6 \mathrm{~mm}$ (right anterior basomedial amygdala), with respect to the bregma.

After completion of the surgical preparation, BP and HR were allowed to stabilize for 20-30 min before any drugs were administered. Microinjections consisted of a total volume of $0.2 \mu 1$ of $0.9 \%$ saline or drug solution infused over 1 min using an infusion pump (BS-MD 1001, Bioanalytical System Inc, West Lafayette, IN, USA). The patency of the injection cannula was always tested immediately before each microinjection and then the position was maintained for $30 \mathrm{~min}$ after beginning the infusion. Following the injection of each drug, BP and HR were monitored for 30 min. Rectal temperature was also measured and maintained at approximately $37^{\circ} \mathrm{C}$ by intermittent heating with a heat lamp. Animals were allowed to breathe spontaneously throughout the experiment. Each rat was used in only one experiment.

To examine the relationship between the extent of diffusion of solution and the volume injected, Evans blue dye was injected in volumes of $0.05-2.0 \mu 1$ into the right anterior basomedial amygdala. One hour later the brains were rapidly removed immediately after decapitation, deepfrozen in $95 \%$ hexane and solid $\mathrm{CO}_{2}$ at -60 to $-65^{\circ} \mathrm{C}$, and sectioned in a cryostat. Sections ( $15 \mu \mathrm{m}$ thick) taken at $45-$ $\mu \mathrm{m}$ intervals through the anterior basomedial amygdala in the coronal or sagittal plane were mounted on slides. Diffusion areas were analyzed microscopically. With volumes greater than $0.5 \mu 1$, diffusion was not limited to within the right anterior basomedial amygdala, and therefore only 0.2 $\mu 1$ of solution was used for further experimentation. The animals were cared for in accordance with the Animal Experimentation Guide of Nagoya University School of Medicine.

\section{Experimental Protocols}

In the first study, bicuculline methiodide (Sigma Chemi- cal Co, St Louis, MO, USA), a GABAA receptor antagonist, was microinjected unilaterally into the anterior basomedial amygdala at doses of $10,50,100 \mathrm{pmol}$ dissolved in $0.2 \mu \mathrm{l}$ of $0.9 \%$ saline. The methiodide salt was selected because it has poor diffusion through the blood-brain barrier! ${ }^{7}$ Because BP and HR, monitored over 30 min, demonstrated a dose-dependent increase, the maximum dose $(100 \mathrm{pmol})$ was used in the following experiments. In addition, microinjections of bicuculline at doses of 50 and $100 \mathrm{pmol}$ were made bilaterally into the anterior basomedial amygdala.

In the second study, an additional Silastic catheter was placed in the right atrium via the jugular vein to allow repeated blood sampling for determination of plasma norepinephrine and epinephrine concentrations. Plasma norepinephrine levels generally provide an index of sympathetic neural activity, and plasma epinephrine provides an index

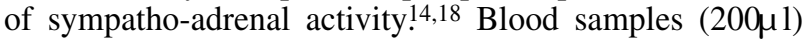
were taken from the Silastic catheter before and 15 and 30 min after microinjection of 100 pmol bicuculline into the anterior basomedial amygdala. Samples were taken with a triple syringe technique to avoid contamination by saline ${ }^{19}$ Plasma norepinephrine and epinephrine levels were determined by high-performance liquid chromatography (M600, Waters Corp, Milford, MA, USA) with an electrochemical detector (ECD-180, Eicom Corp, Kyoto, Japan), as previously described?

In the third study, rats underwent bilateral adrenalectomy under urethane $(1.5 \mathrm{~g} / \mathrm{kg}$, ip) anesthesia, and were then administered a synthetic corticosteroid $(100 \mu \mathrm{g}$ betamethasone sodium phosphate, Shionogi Pharmaceuticals, Osaka, Japan) subcutaneously from the following day onward. Adrenalectomized and sham adrenalectomized rats were individually housed until the experiment started. Seven days after the surgery, $100 \mathrm{pmol}$ of bicuculline was microinjected into the amygdala, and BP and HR were monitored for $30 \mathrm{~min}$. Plasma norepinephrine and epinephrine levels were determined in the adrenalectomized rats, as in the second study.

In the fourth study, hexamethonium bromide (Sigma 
A
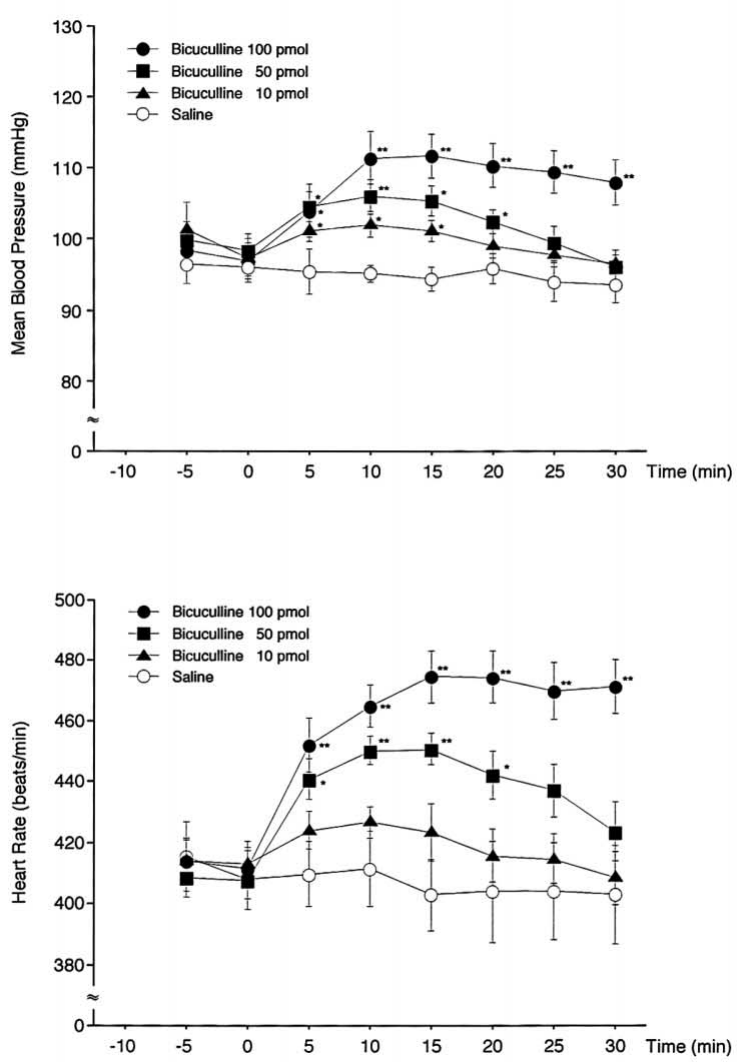

B
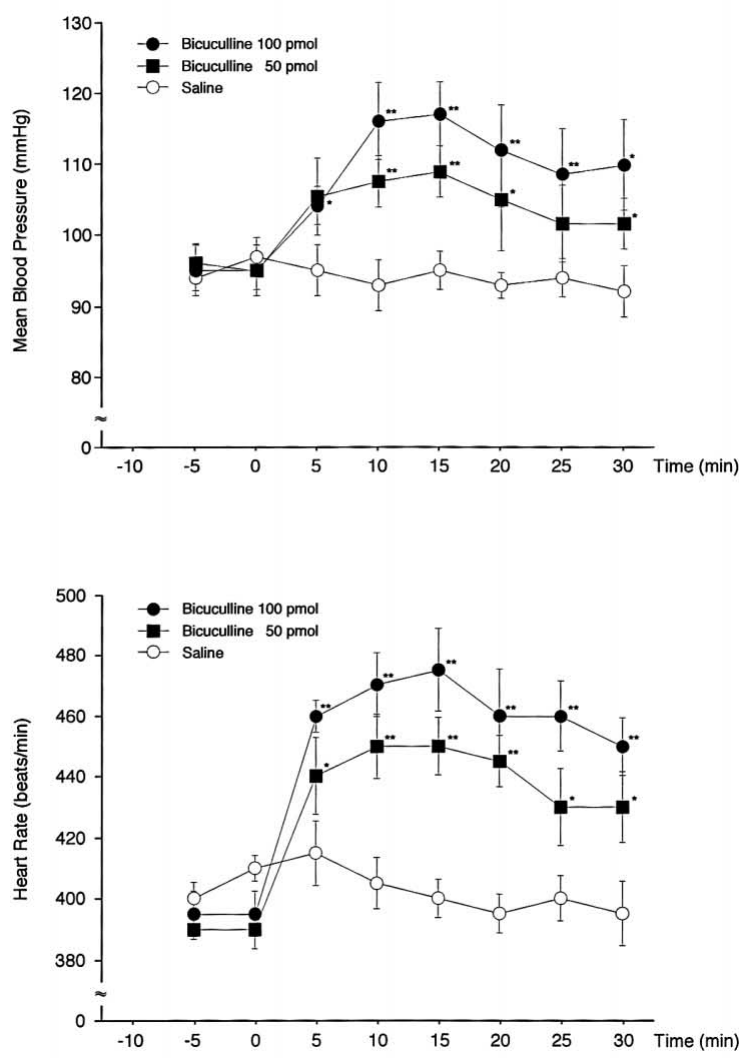

Fig 2. Graphs showing the effects of saline alone $(0.2 \mu 1)$ or with bicuculline $(10,50,100$ pmol $)$ injected unilaterally (A) or bilaterally (B) into the anterior basomedial amygdala on mean blood pressure (Upper) and heart rate (Lower). Values are expressed as means \pm SEM for 5-9 rats. $* \mathrm{p}<0.05, * * \mathrm{p}<0.01$ compared with saline-treated controls.

Chemical Co), a blocker of nicotinic transmission in autonomic ganglia, was first intraperitoneally preinjected at a dose of $40 \mathrm{mg} / \mathrm{kg}$ (concentration of $10 \mathrm{mg} / \mathrm{ml}$ in physiological saline). Once BP and HR had stabilized (usually within $10 \mathrm{~min}), 100 \mathrm{pmol}$ of bicuculline were microinjected into the anterior basomedial amygdala and the hemodynamic variables were then monitored for the next $30 \mathrm{~min}$.

In the fifth study, $100 \mathrm{pmol}$ of bicuculline were dissolved in $0.2 \mathrm{ml}$ of physiological saline and injected intravenously. The catheter was flushed with $0.2 \mathrm{ml}$ of saline, and BP and HR were monitored for the next $30 \mathrm{~min}$.

Finally, in the sixth study, $1 \mathrm{nmol}$ of muscimol (Sigma Chemical Co), a GABA agonist, was microinjected unilaterally into the anterior basomedial amygdala alone or ipsilaterally $5 \mathrm{~min}$ after microinjection of $100 \mathrm{pmol}$ of bicuculline. Again, BP and HR were continuously monitored.

After $100 \mathrm{pmol}$ of bicuculline were injected into the anterior basomedial amygdala, 4 of 62 animals had convulsions and these were excluded from data analysis. Following experimentation all animals were killed, and the brains dissected and fixed by immersion in $10 \%$ neutral formalin. When hardened, the brains were cut and 20 or $40 \mu \mathrm{m}$ sections were stained with the Rucker-Koithan staining procedure. Injection sites were verified by microscopic examination of the brain sections in each animal.

\section{Statistical Analysis}

All quantitative data are expressed as mean \pm SEM values. Statistical analysis was carried out by analysis of variance with Scheffe's test. Differences at the $\mathrm{p}<0.05$ level were considered significant.

\section{Results}

Histological examination of the brains injected with Evans blue dye showed that the diffusion area was always inside the right anterior basomedial amygdala. In the coronal plane, there was no leakage of dye ventral or medial to the anterior basomedial amygdala. The dye spread was approximately $0.3 \mathrm{~mm}$ mediolateral and $0.8 \mathrm{~mm}$ dorsoventral (Fig 1) in diameter. In the sagittal plane the diameter of dye spread was approximately $0.3 \mathrm{~mm}$ anteroposterior, and the diffusion area was within the anterior basomedial amygdala. In some cases there was leakage up the needle tract, but dye diffusion was restricted to within narrow limits.

Fig 2A illustrates the changes in mean BP and HR following the injection of bicuculline $(10,50,100 \mathrm{pmol})$ or saline into the anterior basomedial amygdala. Mean BP rose significantly $5 \mathrm{~min}$ after injection of all 3 doses in comparison with saline-injected rats, reaching maxima at 10-15 min. Subsequently, the pressure gradually returned toward the pretreatment level with the lower doses, but with the 100 pmol dose the change was still significantly greater than the control group value at $30 \mathrm{~min}$. Doses of 50 and $100 \mathrm{pmol}$ of bicuculline increased $\mathrm{HR}$ at $5 \mathrm{~min}$, with maxima reached at $15 \mathrm{~min}$. In the $100 \mathrm{pmol}$ protocol, HR was still significantly increased at $30 \mathrm{~min}$ as compared with the saline-treated 
Table 1 Effects of Bicuculline (100 pmol/0.2 $\mathrm{I}$ Saline) or Saline $(0.2 \mu \mathrm{l})$ Injection Into the Anterior Basomedial Amygdala on Plasma Levels of Norepinephrine and Epinephrine

\begin{tabular}{lccc}
\hline \hline & \multicolumn{3}{c}{ Time (min) } \\
\cline { 2 - 4 } & 0 & 15 & 30 \\
\hline Norepinephrine $(\mathrm{nmol} / \mathrm{L})$ & & & \\
$\quad$ Saline & $3.37 \pm 0.41$ & $3.49 \pm 0.47$ & $3.37 \pm 0.42$ \\
$\quad$ Bicuculline & $3.25 \pm 0.48$ & $8.57 \pm 0.89 * *$ & $10.22 \pm 1.12 * *$ \\
Epinephrine $(\mathrm{pmol} / \mathrm{L})$ & & & \\
$\quad$ Saline & $930 \pm 330$ & $1,640 \pm 440$ & $2,070 \pm 450$ \\
Bicuculline & $600 \pm 160$ & $6,170 \pm 1,580^{*}$ & $6,820 \pm 1,750^{*}$ \\
\hline
\end{tabular}

Values are means $\pm S E M$ for 6 rats. ${ }^{*} p<0.05, * * p<0.01$ compared with the saline-injected control group.

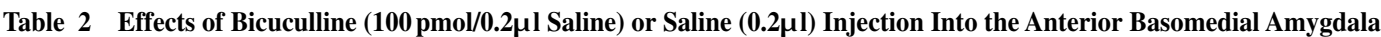
of Adrenalectomized Rats on Plasma Levels of Norepinephrine and Epinephrine

\begin{tabular}{lccc}
\hline \hline & & Time $(\min )$ & \\
\cline { 2 - 4 } & 0 & 15 & 30 \\
\hline Norepinephrine (nmol/L) & & & $3.78 \pm 0.53$ \\
$\quad$ Saline & $3.25 \pm 0.47$ & $3.90 \pm 0.72$ & $9.46 \pm 1.00^{* * *}$ \\
$\quad$ Bicuculline & $2.72 \pm 0.71$ & $8.81 \pm 1.06^{*}$ & \\
Epinephrine (pmol/L) & & & $<100$ \\
$\quad$ Saline & & $<100$ & \\
Bicuculline & &
\end{tabular}

Values are means $\pm S E M$ for $5-6$ rats. ${ }^{*} p<0.05, * * p<0.01$ compared with the saline-injected control group.
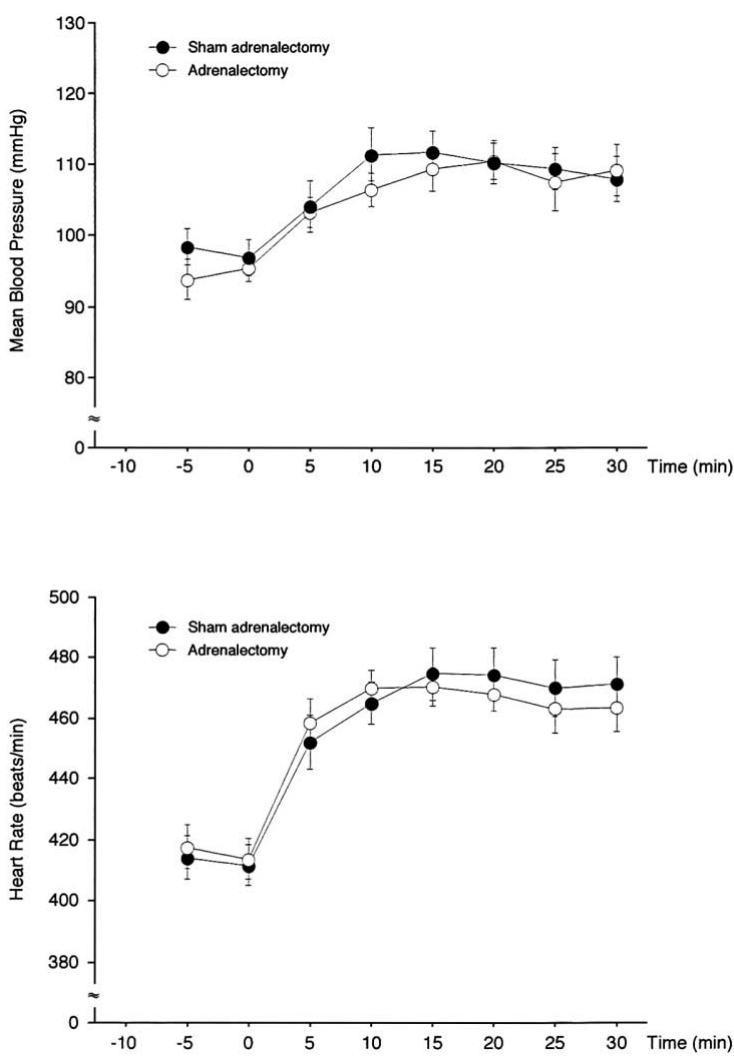

Fig 3. Graphs showing the effects of adrenalectomy on bicuculline $(100 \mathrm{pmol})$ induced pressor response or tachycardia. Adrenalectomy or sham adrenalectomy was performed 7 days before the experiment. Bicuculline was injected into the right anterior basomedial amygdala, and the arterial blood pressure and heart rate were monitored. Values are expressed as means \pm SEM for 6-9 rats.
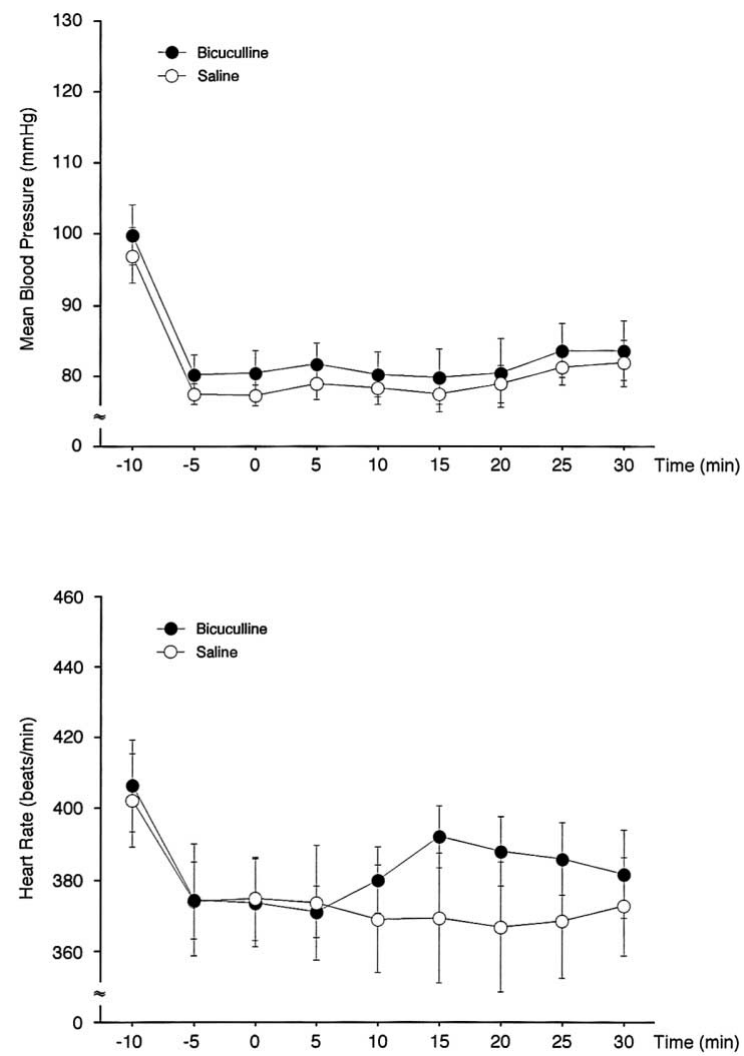

Fig 4. Graphs showing the effects of saline alone or with bicuculline $(100 \mathrm{pmol})$ injected into the anterior basomedial amygdala on mean blood pressure or heart rate after intraperitoneal administration of hexamethonium at a dose of $40 \mathrm{mg} / \mathrm{kg}$, followed $10 \mathrm{~min}$ later by saline, with or without bicuculline, microinjected into the anterior basomedial amygdala. Values are expressed as means \pm SEM for 6-8 rats. 

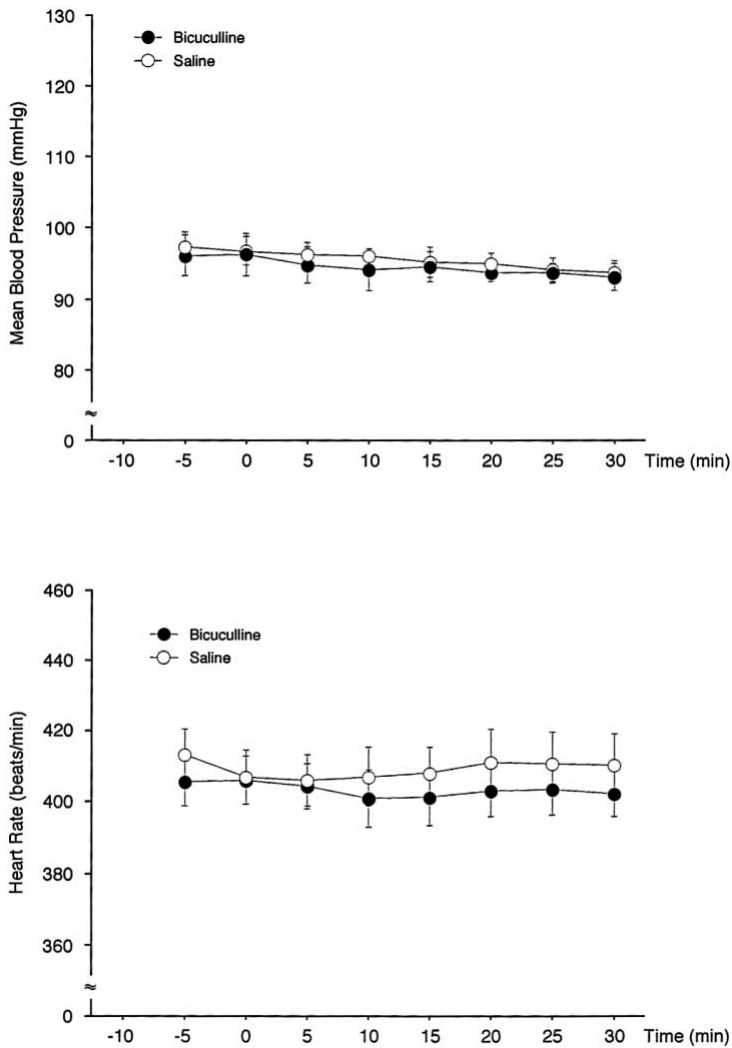

Fig 5. Graphs showing the lack of effect of intravenous bicuculline $(100 \mathrm{pmol})$ or saline alone on mean blood pressure or heart rate. Values are expressed as means \pm SEM for 6-9 rats.

controls.

The effects of bilateral microinjections of bicuculline $(50,100 \mathrm{pmol})$ or saline into the anterior basomedial amygdala on BP and HR are shown in Fig 2B. Dose-related increases in both were observed, similar to the unilateral administration.

Table 1 shows the plasma norepinephrine and epinephrine levels in intact rats after bicuculline microinjection $(100 \mathrm{pmol})$. There was a significant increase in the level of both plasma norepinephrine and epinephrine at 15 and 30 $\min$.

Fig 3 illustrates the effects of 100 pmol of bicuculline on the cardiovascular parameters in the adrenalectomized rats. Following microinjection mean BP began to increase within $5 \mathrm{~min}$, and reached a maximum value at $15-20 \mathrm{~min}$ in both adrenalectomized and sham adrenalectomized animals. Heart rate increased at $5 \mathrm{~min}$, and reached maxima at $15 \mathrm{~min}$

Table 2 summarizes the data for plasma norepinephrine and epinephrine levels in adrenalectomized rats after bicuculline injection $(100 \mathrm{pmol})$. The plasma norepinephrine rose significantly by $15 \mathrm{~min}$ and was still increased at 30 min, as observed in the intact rats. In contrast, epinephrine was below the baseline $(<100 \mathrm{pmol} / \mathrm{L})$ and an increase was not detected throughout the experiment.

Fig 4 depicts the effects of intraperitoneal injection of hexamethonium on the response of the cardiovascular parameters to microinjection of bicuculline into the anterior basomedial amygdala. Mean BP and HR were decreased and the decrease persisted for at least $30 \mathrm{~min}$. Subsequent microinjection of bicuculline into the anterior basomedial
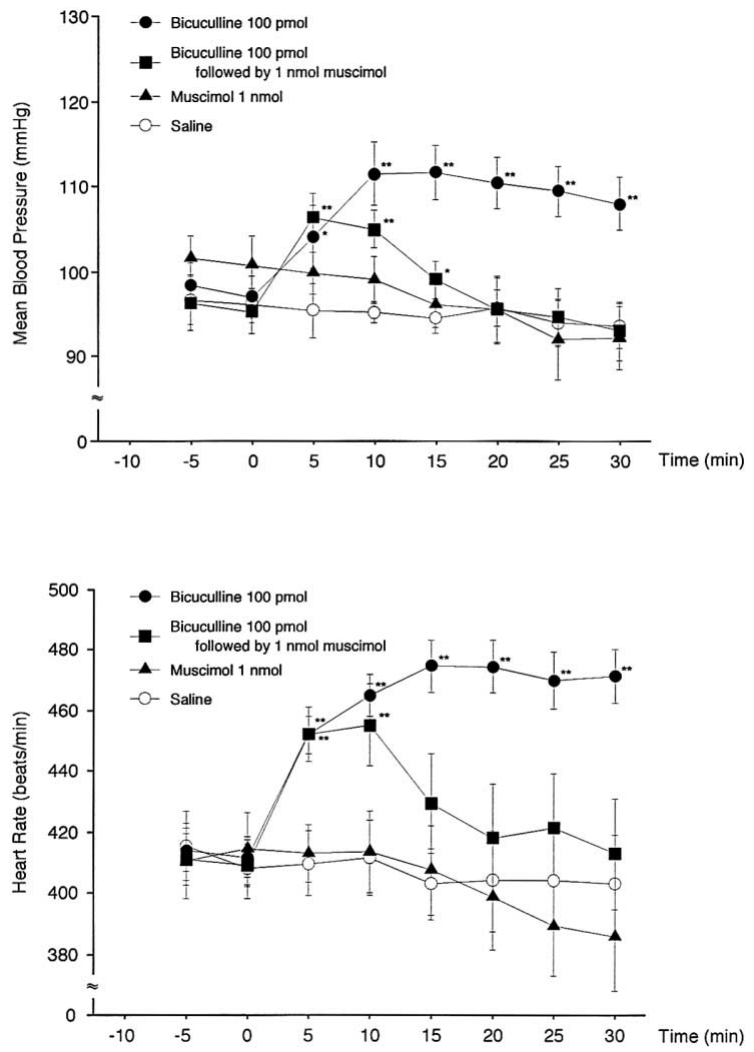

Fig6. Graphs showing the effects of saline alone or with bicuculline $(100 \mathrm{pmol})$ or muscimol $(1 \mathrm{nmol})$ injected into the anterior basomedial amygdala on mean blood pressure (Upper) and heart rate (Lower). In the case of bicuculline followed by muscimol, the microinjection of muscimol was carried out $5 \mathrm{~min}$ after bicuculline administration. Values are expressed as means \pm SEM for $5-8$ rats. ${ }^{*} \mathrm{p}<0.05, * * \mathrm{p}<0.01$ compared with saline-treated controls.

amygdala failed to alter either parameter.

To exclude the possibility that bicuculline administered into the anterior basomedial amygdala had exerted its effects after passing into the peripheral circulation, a 100 pmol dose of bicuculline was injected intravenously and Fig 5 illustrates the lack of effects on either mean BP or HR.

The effects of a microinjection of $1 \mathrm{nmol}$ of muscimol into the anterior basomedial amygdala on mean BP and HR are shown in Fig 6. Although muscimol administration alone had no significant effects on either parameter, the bicuculline-induced pressor and tachycardic responses were inhibited by muscimol.

\section{Discussion}

The present study demonstrated that microinjection of bicuculline into the anterior basomedial amygdala causes an increase in BP and HR, and is associated with an increase in norepinephrine secretion. Bilateral adrenalectomy did not influence the bicuculline-induced hypertension or tachycardia, and intraperitoneal injection of hexamethonium, a ganglionic blocker, inhibited the rise in BP and HR. Intravenous injection of bicuculline did not influence BP and HR, and the bicuculline-induced pressor and tachycardiac responses were inhibited by microinjection of muscimol into the ipsilateral anterior basomedial amygdala.

Bicuculline can induce convulsions when administered 
to the central nervous system ${ }^{21}$ and recently, the relationship between the exicitatory neurotransmission and bicuculline has been shown in rats to involve the basolateral amygdala 11,12 In the present study, bicuculline, injected into the anterior basomedial amygdala, even at the maximum dose used, did not produce convulsions in most rats.

Early neuroanatomical and physiological studies established intimate functional interactions between the amygdala and the other regions of the brain, such as the hypothalamus, the nucleus of the solitary tract, the nucleus accumbens, the thalamus, the cerebral cortex, and the intra-amygdaloid nuclei2 ${ }^{2-25}$ The afferent and efferent connections of the amygdala are complicated, so its contribution to regulation of the cardiovascular system cannot be considered to be simple. In this study, microinjection of the GABA agonist into the anterior basomedial amygdala was found to inhibit the GABAA receptor antagonist-mediated pressor and tachycardiac responses, and we thus propose that blockade of the GABAergic neurons located in the anterior basomedial amygdala brings about excitation of sympathetic output, which results in increased activity in terms of cardiovascular function.

The present study showed that adrenalectomy performed 7 days before the experiment did not suppress the cardiovascular response to bicuculline, an observation that differs from earlier reports that adrenalectomy prevents the tonic inhibitory GABAA receptor effects? 26,27

To determine whether the effects of bicuculline administered into the amygdala were mediated via the sympathetic ganglia, hexamethonium, a blockade of nicotinic ganglionic transmission, was injected intraperitoneally. The subsequent treatment with bicuculline then failed to increase BP and HR, which suggests that hypertension may be caused by neurogenic driving of the vascular smooth muscles and that tachycardia may be a response enacted via direct neural innervation of the heart. The possibility that bicuculline administered into the amygdala exerted its effects through leakage into the systemic circulation was excluded by the lack of response to bicuculline given intravenously at the same dose.

Anesthetics, which have general central nervous system depressant effects, might be expected to change the character of cardiovascular responses produced by chemical stimulation of the central nervous system. Indeed, both BP and HR responses to pharmacological agents have been found to be significantly different in conscious as compared to anesthetized animals.,28 However, a number of previous studies regarding the role of the amygdala in cardiovascular effects have been performed under anesthesia9,10,12 and so further investigation of the role of the amygdala via the GABAA receptors in anesthetized rats is required.

In conclusion, the present results provide evidence that GABAA receptors located in the anterior basomedial amygdala play a part in the cardiac response via an increase in sympathetic drive. This raises the possibility of a tonic GABAergic inhibition of sympathetic outflow at the anterior basomedial amygdala.

\section{References}

1. Murakami M, Mikuniya A, Suto N, Okubo T, Shinozaki N, Okumura K. Effects of cardiac sympathetic nerve stimulation on the left ventricular end-systolic pressure-volume relationship and plasma norepinephrine dynamics in dogs. Jpn Circ J 1997; 61: 864-871.

2. Harada K, Ohmori M, Fujimura A, Ohashi K. Effect of amezinium metilsulfate on the finger shin vasoconstrictor response to cold stim- ulation and venoconstrictor response to noradrenaline. Jpn Circ J 1998; 62: 824-828.

3. DiMicco JA, Monroe AJ. GABAB receptors in the dorsomedial hypothalamus and heart rate in anesthetized rats. Brain Res 1998; 788: $245-250$.

4. Peng Y-J, Gong Q-L, Li P. GABAA receptors in the rostral ventrolateral medulla mediate the depressor response induced by stimulation of the greater splanchnic nerve afferent fibres in rats. Neurosci Lett 1998; 249: 95-98.

5. Butcher KS, Cechetto DF. Neurotransmission in the medulla mediating insular cortical and lateral hypothalamic sympathetic responses. Can J Physiol Pharmacol 1998; 76: 737-746.

6. Soltis RP, Cook JC, Gregg AE, Stratton JM, Flickinger KA. EAA receptors in the dorsomedial hypothalamic area mediate the cardiovascular response to activation of the amygdala. Am J Physiol 1998; 275: R624-R631.

7. Stotz-Potter E, Benarroch E. Removal of GABAergic inhibition in the mediodorsal nucleus of the rat thalamus leads to increases in heart rate and blood pressure. Neurosci Lett 1998; 247: 127-130.

8. Özkutlu U, Coskun T, Onat F, Yegen BÇ, Oktay S. Cardiovascular effects of centrally active cholinomimetics in conscious and anesthetized rats: The role of amygdala. Brain Res Bull 1995; 37: 569573.

9. Sanders SK, Shekhar A. Blockade of GABAA receptors in the region of the anterior basolateral amyglada of rats elicits increases in heart rate and blood pressure. Brain Res 1991; 576: 101-110.

10. Ohta H, Watanabe S, Ueki S. Cardiovascular changes induced by chemical stimulation of the amygdala in rats. Brain Res Bull 1991; 26: $575-581$.

11. Sajdyk TJ, Shekhar A. Excitatory amino acid receptor antagonist block the cardiovascular and anxiety responses elicited by $\mathrm{Y}-$ aminobutyric acida receptor blockade in the basolateral amygdala of rats. J Pharmacol Exp Ther 1997; 283: 969-977.

12. Soltis RP, Cook JC, Gregg AE, Sanders BJ. Interaction of GABA and excitatory amino acids in the basolateral amygdala: Role in cardiovascular regulation. J Neurosci 1997; 17: 9367-9374.

13. Petrovich GD, Risold PY, Swanson LW. Organization of projections from the basomedial nucleus of the amygdala: A PHAL study in the rat. J Comp Neurol 1996; 374: 387-420.

14. Haruta K, Iguchi A, Matsubara T, Itoh K, Chen C-L, Yoshida S, et al. Stimulation of muscarinic cholinoceptive neurons in the hippocampus evokes a pressor response with bradycardia. Life Sci 1992; 50: $427-433$.

15. Hori H, Haruta K, Nanki M, Sakamoto N, Uemura K, Matsubara T, et al. Pressor response induced by the hippocampal administration of neostigmine is suppressed by M1 muscarinic antagonist. Life Sci 1995; 57: $1853-1859$.

16. Pellegrino LJ, Pellegrino AS, Cushman AJ. A stereotaxic atlas of the rat brain, 2nd edn. New York: Plenum Press; 1967.

17. Remler MP, Marcussen WH. Bicuculline methiodide in the bloodbrain barrier-epileptogen model of epilepsy. Epilepsia 1985; 26: $69-$ 73.

18. Inoko M, Fujita M, Nakao I, Tamaki S, Watanuki M, Hashimoto T, et al. Effects of angiotensin-converting enzyme inhibition on sympathetic tone in patients with mild to moderate heart failure. Jpn Circ J 2001; 65: 395-398.

19. Iguchi A, Burleson PD, Szabo AJ. Transjugular hepatic vein cannulation in rats with nonisotopic in vivo verification. Am J Physiol 1979; 237: $\mathrm{H} 730-\mathrm{H} 733$.

20. Iguchi A, Gotoh M, Matsunaga H, Yatomi A, Honmura A, Yanase $\mathrm{M}$, et al. Mechanism of central hyperglycemic effect of cholinergic agonists in fasted rats. Am J Physiol 1986; 251: E431-E437.

21. Lloyd KG, Munari C, Worms P, Bossi L, Bancaud J, Talairach J, et al. The role of GABA mediated neurotransmission in convulsive states. In: Costa E, DiChiara G, Gessa GL, editors. GABA and benzodiazepine receptors: Advances in biochemical psychopharmacology, Vol 26. New York: Raven Press; 1981: 199-206.

22. Krettek JE, Price JL. A description of the amygdaloid complex in the rat and cat with observations on intra-amygdaloid axonal connections. J Comp Neurol 1978; 178: 255-280.

23. Schwaber JS, Kapp BS, Higgins G. The origin and extent of direct amygdala projections to the region of the dorsal motor nucleus of the vagus and the nucleus of the solitary tract. Neurosci Lett 1980; 20: $15-20$.

24. Robinson TG, Beart PM. Excitant amino acid projections from rat amygdala and thalamus to nucleus accumbens. Brain Res Bull 1988; 20: $467-471$.

25. Van der Kooy D, Koda LY, McGinty JF, Gerfen CR, Bloom FE. The organization of projections from the cortex, amygdala, and hypothalamus to the nucleus of the solitary tract in rat. J Comp Neurol 1984; 
224: $1-24$.

26. Martin DS, Segura T, Haywood JR. Cardiovascular responses to bicuculline in the paraventricular nucleus of the rat. Hypertension 1991; 18: $48-55$.

27. Gören Z, Aslan N, Berkman K, Oktay S, Onat F. The role of amyglada and hypothalamus in GABAA antagonist bicuculline-induced cardio- vascular responses in conscious rats. Brain Res 1996; 722: 118-124.

28. Callera JC, Bonagamba LGH, Nosjean A, Laguzzi R, Machado BH. Activation of GABAA but not GABAB receptors in the NTS-blocked bradycardia of chemoreflex in awake rats. Am J Physiol 1999; 276: H1902-H1910. 